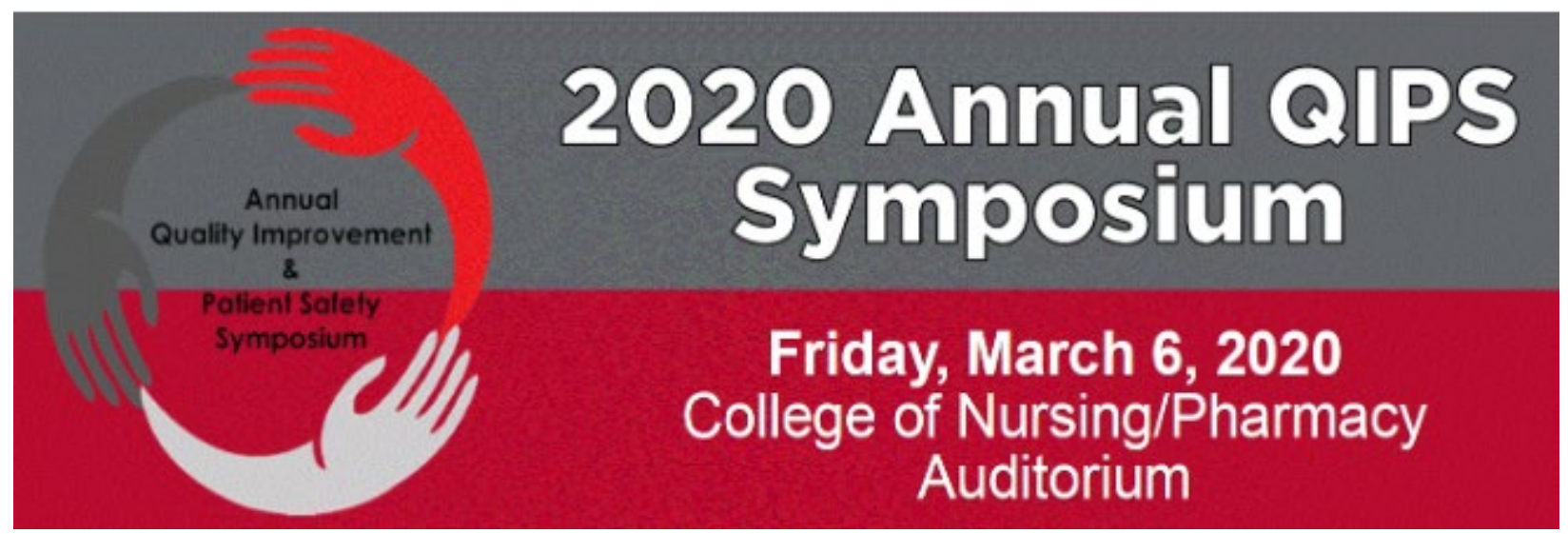

\title{
Ultrasensitive RNA in Situ Hybridization for Kappa and Lambda Light Chain mRNA in Marginal Zone Lymphoma Demonstrates Comparable Performance to Flow Cytometry
}

Michael M. Franklin Chelsey Deel, Mohammad A. Vasef MD

\section{Objectives:}

Evaluation of light chain restriction is critical to establish clonality in B cell lymphoproliferative disorders (LPDs). Immunohistochemistry $(\mathrm{IHC})$ or in situ hybridization $(\mathrm{ISH})$ are commonly used to assess light chain restriction in formalin fixed, paraffin embedded (FFPE) tissues. However, except for cases with plasma cell differentiation, these techniques often fail to identify immunoglobulin light chains. An ultrasensitive technique, RNAscope, has been recently introduced which can identify light chains in cases of B cell LPDs. We analyzed the utility of this ultrasensitive method in detection of clonality and correlated with flow cytometry results when available.

\section{Methods:}

A tissue microarray (TMA) was constructed using $1.6 \mathrm{~mm}$ diameter tissue punches of $31 \mathrm{FFPE}$ tissue blocks from 27 cases (figure 1) which were previously characterized as marginal zone lymphoma (MZL) by a combination of morphology, IHC, and/or flow cytometry. Cases included 8 nodal and 19 extra nodal MZL. In 2 cases, additional blocks were included to assess reproducibility. For ultrasensitive ISH RNAscope assay, $4 \mu$ thickness tissue sections were hybridized using kappa and lambda probes, incubated overnight, counterstained with hematoxylin, cover-slipped and reviewed blindly without knowledge of prior flow cytometry results.

\section{Results:}

Of 18 cases with evaluable staining, 15 were clonal and 3 were polytypic. Flow cytometry was available in 14 of these 18 cases with concordance in $13 / 14(93 \%$ ) (figure 2). The discordant case was polytypic by flow cytometry but kappa restricted by RNAscope. The false negative flow results could be due to sampling issues. In 6 cases, staining failed and could not be evaluated.

\section{Conclusion:}

Ultrasensitive RNAscope is a reliable assay in the detection of clonality in FFPE tissue, particularly where fresh tissue is not available for flow cytometry. In addition, our results confirm and further expand prior observations that RNAscope is a highly sensitive and specific assay with high concordance with flow cytometry.

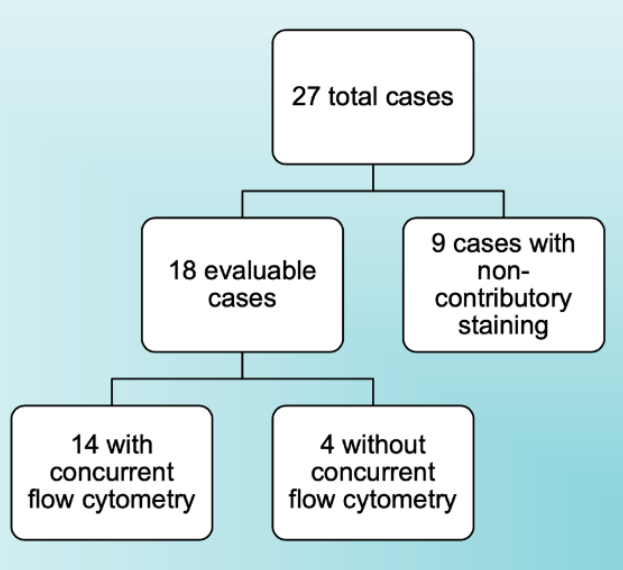

Figure 1. Flowchart of all cases in study.

\begin{tabular}{|c|c|c|c|}
\hline Diagnosis & $\begin{array}{c}\text { Total } \\
\text { cases }\end{array}$ & $\begin{array}{c}\text { Concordant with } \\
\text { flow cytometry }\end{array}$ & $\begin{array}{c}\text { Discordant with flow } \\
\text { cytometry }\end{array}$ \\
\hline $\begin{array}{c}\text { Nodal marginal zone } \\
\text { lymphoma }\end{array}$ & 6 & $6 / 6(100 \%)$ & $0 / 6(0 \%)$ \\
\hline $\begin{array}{c}\text { Extra nodal marginal zone } \\
\text { lymphoma (MALT lymphoma) }\end{array}$ & 10 & $5 / 6(83 \%)$ & $1 / 6(17 \%)$ \\
\hline $\begin{array}{c}\text { Splenic marginal zone } \\
\text { lymphoma }\end{array}$ & 2 & $2 / 2(100 \%)$ & $0 / 2(0 \%)$ \\
\hline
\end{tabular}

Figure 2: Table of evaluable cases. 